\title{
Fuentes pobres, métodos complejos. Producción agroganadera y sociedad en un área fronteriza del Río de la Plata tardocolonial: un análisis estadístico ${ }^{1}$
}

\author{
Julio César Djenderedjian
}

Universidad de Buenos Aires, Argentina

El estudio económico de casos de frontera en la América hispana colonial sufre a menudo por la pobreza y escasez de fuentes cuantitativas. Aquí trataremos de mostrar cómo logramos extraer utilidad de un registro de pago de diezmos de granos y ganado efectuado en la actual provincia argentina de Entre Ríos hacia 1808-1809, de valor no sólo por la absoluta excepcionalidad del documento, sino por tratarse de un área de rápido crecimiento agropecuario en las décadas previas, que podría haber sido un anticipo del desarrollo experimentado por la economía ganadera argentina en la primera mitad del siglo XIX.

PALABRAS ClaVE: ganadería, agricultura, estadística, clusters, Río de la Plata.

The economic analysis of frontier cases in Latin America often endures acute problems because of lack or stinginess of the sources. Here we will try to show how to extract full profit of a grain and livestock tithe register from present-day Argentine province of Entre Rios, dated 1808-1809, not only valuable because of its rarity: that area had been experiencing a rapid economic growth in the previous decades, which probably anticipated the quick development of the argentine cattle economy on the first half of the XIX century.

KeYwords: cattle, agriculture, statistics, cluster analysis, Río de la Plata.

Para todo aquel que haya trabajado sobre casos de fronteras en la América hispana no resultará una novedad la pobreza y escasez de las fuentes cuantitativas con que, seguramente, ha debido toparse, en especial si se trata de épocas anteriores a la mitad del siglo XIX. En lo que atañe al Río de la Plata, la renovación historiográfica de los últimos años, sobre todo en temas relacionados con la economía agraria colonial, ha traído avances realmente significativos; sin embargo, esos avances (basados fun-

1 Deseo agradecer los valiosos comentarios efectuados a versiones previas de este artículo por parte de los colegas Javier Balsa, Luis Acosta, Silvia Palomeque, Roberto Schmit y árbitros anónimos de esta revista. 
damentalmente en la puesta en valor de fuentes antes no trabajadas y en una mirada crítica sobre el conjunto de afirmaciones recibidas y aceptadas durante mucho tiempo) han encontrado sólidos escollos en las áreas marginales, debidos justamente a esa escasez y parquedad de las fuentes. ${ }^{2}$ A menudo ocurre asimismo que, aun cuando contemos con algunos datos útiles, es posible que nos falte el background necesario para aprovecharlos en forma más o menos integral. Por ejemplo, si hay datos de producción, eso no significa que podamos cruzarlos con información complementaria de igual valor, ya que los padrones poblacionales y los registros de tierras, en tiempos preestadísticos y en regiones marginales, no suelen caracterizarse por su precisión o abundancia. Esto suele ser siempre desalentador: es justamente en esas regiones nuevas, de poblamiento sumario y recursos feraces, donde se situaron los inicios de un impetuoso desarrollo ganadero que, a fines del período colonial, pareció augurar al Río de la Plata los rasgos de su rostro económico en el largo y tempestuoso siglo que habría de sobrevenir. ${ }^{3}$ Pareciera entonces que, para entender algunas de las claves fundamentales de nuestra historia en la de esas fronteras despojadas, resultara imprescindible valerse del variable cúmulo de información cualitativa, con el riesgo consecuente de dejarnos llevar por sus impresiones, y renunciando de antemano a un análisis detallado, o sucumbiendo a la presunción de que un caso individual pueda generalizarse. De todos modos, esa misma información cualitativa requiere a menudo ser explicada; y, si de cualquier manera hemos hallado datos de cierta calidad capaces de ser utilizados, sería lamentable que no pudiéramos hacerlo por faltarnos otras bases en las cuales apoyarlos. Es entonces momento de echar mano a técnicas un poco más complejas que lo habitual: se trata de encontrar un criterio de distribución homogéneo, una forma de repartir los datos en una imagen precisa, capaz de permitirnos un análisis detallado del área de nuestro interés; una imagen que describa una realidad que las fuentes cualitativas confirmen, pero no determinen. Se trata entonces de refinar un poco los instrumentos de ese análisis; a continuación mostraremos los resultados obtenidos en la aplicación a un caso concreto.

2 Una buena y reciente mise au point de la fecunda renovación historiográfica de los últimos años en Gelman, Jorge y Garavaglia, Juan Carlos: "Mucha tierra y poca gente: un nuevo balance historiográfico de la historia rural rioplatense (1750-1850)" en Historia agraria, VIII-15, Murcia, 1998, págs. 29-50.

3 Ver Halperín Donghi, Tulio: Revolución y guerra, Siglo XXI, México, 1972, págs. 35 y ss. 


\section{a) Fuentes y métodos}

Los datos que analizaremos corresponden a una percepción del diezmo de trigo y animales del norte de la actual provincia argentina de Entre Ríos en los años de 1808 y 1809, que nos ofrecen detalles de la producción individual obtenida por las explotaciones involucradas. ${ }^{4}$ Nuestros objetivos son obtener una imagen sintética y clara del perfil productivo regional general y del de las distintas áreas que la formaban, valiéndonos para ello de la observación y clasificación de las unidades de explotación cuyos datos poseemos. La orientación productiva de las mismas, que suponemos ligada a la presencia relativa de los diferentes tipos de animales o de cultivos, nos brindará el punto de partida para esa clasificación. La distribución del stock ganadero y de la producción agrícola en las diferentes áreas nos develará las características productivas de esa frontera y nos permitirá intuir rasgos sobre los cuales no poseemos fuentes, así como nos ayudará a ordenar la dispersa y fragmentaria evidencia cualitativa restante. Nos brindará asimismo algunas pautas para entender las particularidades culturales, sociales y regionales que se ocultaban detrás de los datos.

A efectos de este estudio, y de acuerdo a los objetivos especificados, consideramos adecuado reunir las explotaciones individuales según su orientación productiva; para ello, decidimos emplear la técnica estadística de agrupación en clusters. En términos simples, la misma se utiliza para distribuir los casos individuales en grupos que luego serán objeto del análisis, ya que cada grupo poseerá distintas peculiaridades, definidas a través de un conjunto de variables que comparten, en medida lo suficientemente significativa, una determinada cantidad de los casos. En cada uno de ellos, cada variable posee un determinado peso (por ejemplo: una unidad productiva será tanto más agrícola cuanto la presencia de cultivos sea mayor con respecto a la existencia de animales; y será más ganadera en la medida en que aumente la parte del capital productivo invertida en vacunos).

4 La recaudación del diezmo, un impuesto eclesiástico (el 10\% de la producción) era rematada regularmente dadas las dificultades que suponía su cobranza directa; en nuestro caso, la Junta de Diezmos de Buenos Aires (de la cual dependía el norte entrerriano) decidió que era mejor encargar a alguien, por única vez, la recolección directa (percepción), ya que no parecía haber interesados en pagar la alta base establecida para el remate de ambos años, y también para que el total recaudado, deducidos los gastos, sirviera de guía en el establecimiento de nuevos montos mínimos para los remates subsiguientes, dado que por entonces se conocía bastante poco acerca de lo que podía esperarse de esa remota región de frontera de impetuoso progreso económico. La documentación se encuentra en el Archivo General de la Nación, Buenos Aires (en adelante AGN), IX-20-5-7, Hacienda, Tabacos, Misiones, Arbitrios de Santa Fe, 1761-1807. 
El peso relativo promedio de las variables constituye un punto de referencia (centroide), a partir del cual, a mayor o menor distancia, se agrupan los casos individuales. Los más cercanos serán aquellos cuyas características sean más similares a las de éste, y, por el contrario, cuando un caso se ubique a mayor distancia, compartirá en menor medida esas características. Según la cantidad de centroides que elijamos (es decir, según la cantidad de clusters que fijemos para el análisis) serán los grupos que obtengamos; en unos, pesarán más determinadas variables que otras, dado que los casos contienen los caracteres de éstas en una proporción no homogénea. Debemos tratar de que la cantidad de clusters que fijemos sea operativa para nuestro estudio, es decir que refleje las características naturales de los casos sin que el nivel de las diferencias entre ellos resulte en una cantidad de agrupamientos demasiado grande, o que las similitudes impliquen que la mayor parte de los casos se agrupe en un solo cluster. Asimismo (y mucho más importante), debemos tratar que las variables elegidas sean relevantes y puedan ser comparadas, y que las diferencias entre los valores absolutos de ellas no se constituya en un problema para el análisis. ${ }^{5}$

\section{El lugar}

Nuestro interés se centrará en tres porciones algo arbitrarias de la actual provincia de Entre Ríos, cuya elección debemos estrictamente a los datos disponibles. ${ }^{6}$ Primero, en la parte occidental de la provincia, el área que en el mapa figura con el número 1 , y que abarca a los contribuyentes situados a la vera del río Guayquiraró y a los de Diego López, La Mula, El Sauce, Guerreros, las Yeguas, Lucas y Moreira, no marcados en el mapa por razones de escala. Podemos decir que esta vasta área, según los datos

5 Dado que, por ejemplo, en el método Ward, las distancias euclídeas de los casos al centroide se elevan al cuadrado, las diferencias entre los valores absolutos de cada variable aumentan si una de ellas tiene mucho más peso que las otras; entonces, es necesario estandarizarlas (es decir dividir las variables por su desvío), o admitir su importancia y mantener los valores absolutos, que es lo que haremos aquí.

6 A inicios del siglo XIX la presencia allí de autoridades era aún precaria. El área que rodea a la actual ciudad de Paraná y va hasta el río Hondo fue reivindicada desde antiguo por la ciudad de Santa Fe; por lo que al fundarse la villa de Concepción del Uruguay (1782) su jurisdicción quedó en entredicho por los poco claros límites establecidos tanto con otros centros poblados de la futura provincia como con los territorios de Misiones y Corrientes. El obispo de Buenos Aires Lue y Riega, hacia 1806, fijó los límites del curato de Concepción bajo una forma irregular que abarcaba las áreas marcadas con números en el mapa, laudando en diversos pleitos por sus confines. Cuando se efectuó la recaudación del diezmo de 1808 y 1809, el colector se ajustó estrictamente a las extrañas medidas de aquella jurisdicción. 
de un censo de 1805, contaría entonces con unos 150 ó 200 habitantes estables. ${ }^{7}$ Parece ser que ésta era quizá el área más ganadera de toda la porción norte de la actual provincia de Entre Ríos. ${ }^{8}$ La siguiente área comprende toda la porción oriental del norte entrerriano, desde el Arroyo de la China hasta el Yeruá. Esta área, que la bibliografía tradicional nos indica que

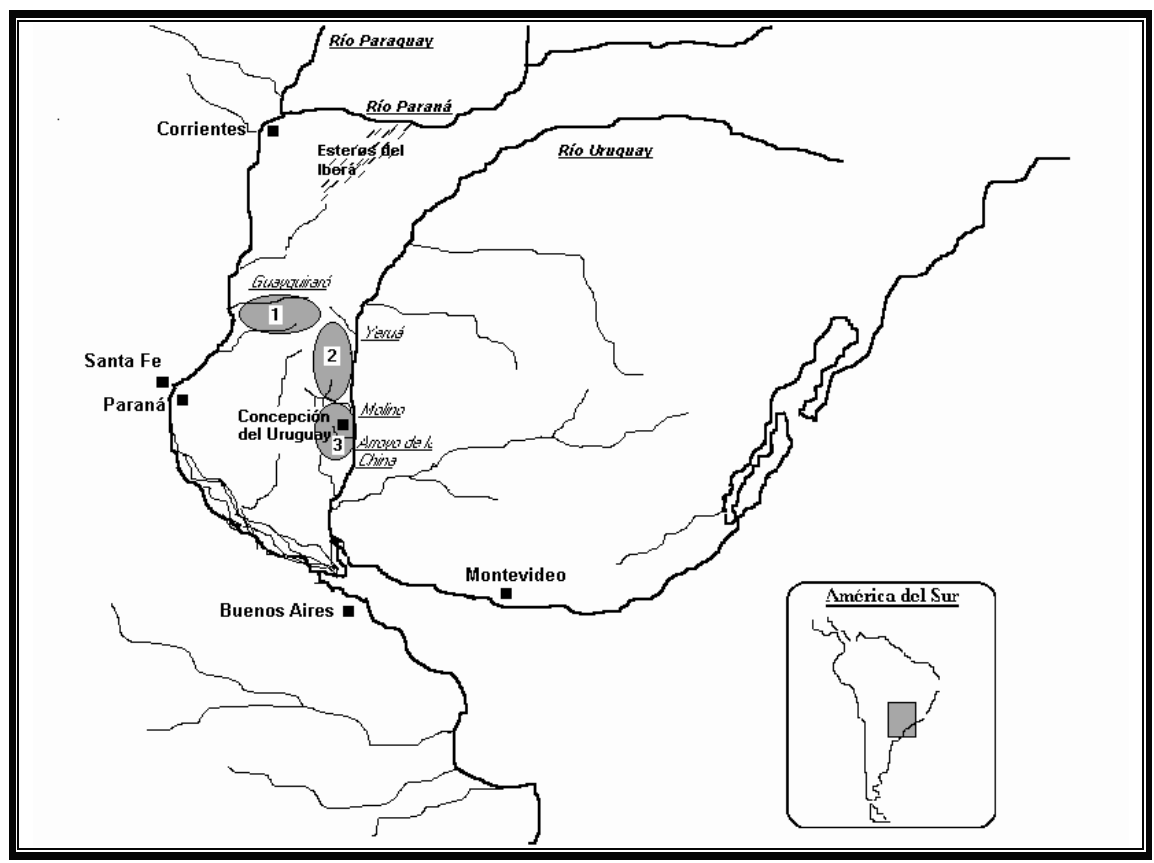

El litoral argentino a fines de la época colonial y su situación relativa en Sudamérica. Los cursos de agua aparecen subrayados. Elaboración propia sobre el mapa de Martin de Moussy, Victor: "Carte des Provinces d'Entre-Rios, de Santa Fe et de la Bande Orientale..." Paris, 1865; incluido en la obra del mismo autor, Description Géographique et Statistique de la Confédération Argentine. Paris, Firmin Didot, 1860-64, Atlas (2da. edición, 1873), pl. VIII.

7 Esto surge de los datos de las familias asentadas a la vera de los arroyos mencionados, salvo el caso del Guayquiraró, que el censista de 1805 dividió y juntó, no sabemos por qué, con los del Hondo y el Feliciano. AGN, IX-31-8-8, Justicia, 50, 1446.

8 Un padrón de "estancieros" de Guerreros y Guayquiraró da cuenta de 23 establecimientos en 1805 , de los cuales hemos identificado a 15 en la percepción diezmal de 1808-9; sus patrimonios totales, deducidos a partir de los montos de ganado entregado, rondarían en conjunto las 55.000 cabezas (de animales de todas clases, ocupando el vacuno alrededor del 70\%), lo cual implica una media de 3.703 por establecimiento. 
comenzó a poblarse en forma estable hacia 1770, alrededor del caserío del Arroyo de la China (hoy ciudad de Concepción del Uruguay), con unos pocos labradores provenientes de la zona de Gualeguaychú, a inicios del siglo XIX contaba ya con una población considerable, que quizá llegaría a unos 800 a 1.000 habitantes, buena parte de los cuales residía en la propia Concepción, por entonces ya agraciada con el título de villa. ${ }^{9}$ La progresión del poblamiento debió de haber sido rápida, continua y general, y no sólo alimentada por el crecimiento vegetativo; todo parece apuntar a que la mayor disponibilidad de tierras fue un factor importante en el estímulo de la migración receptiva a inicios del siglo XIX; ésta provenía en su mayor parte de los pueblos de las misiones guaraníes, por entonces en franca disolución, y de los más poblados campos de Corrientes, en especial los de la porción sureste. ${ }^{10}$ Una muestra del rápido progreso económico y aun demográfico de la región: los remates de los diezmos de cuatropea y granos de 1805, pregonados por primera vez en el ámbito local (hasta entonces lo habían sido en Buenos Aires), llegaron a la astronómica cifra de 2.130 pesos, aumentando al año siguiente a 2.687. Valga apuntar aquí que esos mismos diezmos, antes de 1804 , nunca habían pasado de mil. ${ }^{11}$

9 Esa es la cifra que obtendremos si retrotraemos a 1800 los datos del área para 1820 (aproximadamente 2.100 personas); suponiendo una tasa de crecimiento del $3 \%$ anual, que en este contexto no es irrazonable, y teniendo en cuenta la llegada de muchas familias de la Banda Oriental durante los disturbios de tiempos revolucionarios. Ver Schmit, Roberto: "Población, migración y familia en el Río de la Plata. El oriente entrerriano, 1820-1850", en Anuario IEHS, 15, Tandil, 2000. Sobre los inicios del poblamiento, ver Pérez Colman, César: Historia de Entre Ríos. Epoca colonial, Imprenta de la Provincia, Paraná, 1936/7, vol. II, págs. 11 y ss.

10 “... devo hazer presente a V.S. que el año passado de 84 u 85 Se formo padron de aquel vezindario [la jurisdicción de Concepción del Uruguay] ... para informar a V.S. el numero de Vezinos que tenia aquella Villa, y se hallaron 125 familias, de donde se infiere que oy hacendera pr. lo menos a 200, segun las que posteriormte. se han casado, y los que se han arraigado...” Juan del Mármol al Gobernador Intendente, Buenos Aires, 12 de diciembre de 1786, en AGN, IX-31-5-1, Justicia, 20, 555, fs. 2 r., subrayado nuestro. Sobre la disponibilidad de tierras y la inmigración, un testimonio podría resultar ilustrativo: don Miguel Pucheta escribía en 1794 que “... La urgente necesidad de buscar terreno en que con [comodidad descan]sasen [mis] haciendas ... [me] hizo mudar de destino, transmigrandolas de la ... jurisdiccion de Corrientes a los campos de Taces, los quales ... se hallan comprehendidos con todo su vecindario vajo de la del mando de Vm.." Dn. Miguel Geronimo Pucheta, vecino y habitante en la Capilla de San Roque (Corrientes) a José de Urquiza (por entonces comandante militar de Concepción), San Roque, 8 de noviembre de 1794. En AGN, VII, 1463, Archivo Urquiza, I, fs. 1 v. A lo largo del siglo XIX esta expulsión de correntinos hacia los campos entrerrianos no haría sino afianzarse y aumentar. Ver Schmit: "Población, migración...".

11 Sobre el remate de 1805, véase el dictamen de Nicolás del Campo, Buenos Aires, 15 de enero de 1805, en AGN, IX-13-5-7, 2; sobre lo recaudado en 1806, AGN, IX-7-3-2, "Quadrante de diezmos". El registro indica que los 2.687 pesos se pagaron sólo por los diezmos de cuatropea, pero dado que no figura el importe de los granos y tanto antes como después ambos rubros se remataron juntos, suponemos que también ese año y esa cifra corresponden a ambos. 
Hemos subdividido a su vez a esta área en dos: una ganadera y de colonización más reciente, al norte del Molino (que figura en el mapa con el número 2); y la más antigua, más poblada y también más orientada hacia la agricultura, que rodeaba a la villa de Concepción, y que en el mapa tiene el número 3. En esta última se encuentran sin embargo dos grandes unidades productivas (Joseph de Urquiza e Ygnacio Sagastume, un rico comerciante y estanciero local). Se trata de explotaciones netamente ganaderas, pero ha sido imposible separarlas del área triguera dado que sus lindes se encuentran muy cerca de Concepción. ${ }^{12}$

Tenemos de esta forma tres áreas que, para simplificar, designaremos en lo sucesivo con los números que aparecen en el mapa. No contamos con padrones de población aceptables de ninguna de esas áreas; sin embargo, tanto los disponibles para otras zonas cercanas como los estudios efectuados con datos del censo de 1820 (el primero que puede calificarse de tal) nos indican la predominancia de unidades familiares simples y extendidas, vinculadas muchas veces por lazos de parentesco y de residencia perilocal, con una relativamente alta cantidad de hijos en promedio; esto es, el trasfondo de una sociedad de campesinos-pastores en una frontera de ocupación reciente, cuya productividad descansaba en gran parte en la mano de obra aportada por la propia familia. ${ }^{13}$

\section{b) Los productores y la producción}

La recaudación diezmal de 1808 y 1809 abarca a 155 productores con datos..$^{14}$ No tenemos forma de medir la representatividad de la fuente, a pesar de que contamos con un cálculo impresionista efectuado en la época acerca de la cantidad de unidades productivas activas en la zona, y que nos indicaría que aquéllas no constituyen la totalidad. ${ }^{15}$ En estos casos, suele legítima-

12 La propiedad de Sagastume tenía como frente el arroyo Gualeguaychú, y la de Urquiza el Colman. Ambas se extendían considerablemente hacia el interior.

13 Un estudio de los padrones del este entrerriano de inicios del siglo XIX en Djenderedjian, Julio: "Una Arcadia criolla. Producción ganadera familiar y poblamiento de la frontera norentrerriana a inicios del siglo XIX", ponencia en reunión de la Red de Estudios Rurales, Instituto Ravignani, Facultad de Filosofía y Letras, U.B.A., Buenos Aires, septiembre de 1999. Sobre la evolución poblacional del oriente entrerriano a lo largo del siglo XIX, ver Schmit: "Población, migración...".

14 De los 156 productores descontaremos a Francisco Rotela, a quien no se le pudo cobrar el impuesto a causa de que al momento de la recaudación se hallaba en Buenos Aires.

15 "Las estancias y chacaras que se hallan en el dia establecidas en esta Jurisdiccion poco mas o menos alcanzan el numero de tres cientas..." Expediente sin carátula ni foliación, cuya primer foja comienza con las palabras "Mui Yltre. Cavildo Justa. y Regyto...", fechado en Concepción del Uruguay, 16 de febrero de 1793, en AGN, IX-35-1-5. 
mente sospecharse que las que más han escapado al registro son las unidades de menor dimensión; para nuestra tranquilidad podemos decir que parte de éstas al menos no lo ha hecho. ${ }^{16}$ Poseemos el procreo de vacunos, equinos, mulares y ovinos de ambos años, además del trigo producido, con una merma en lo que respecta a la cosecha de 1808 debida entre otras cosas a las pérdidas consiguientes al largo tiempo transcurrido hasta el cobro del diezmo por parte del recaudador. ${ }^{17}$ Como era usual en estos casos, el impuesto se cobraba en especie, aunque buena parte de ellas era comprada al recaudador por el propio productor (ya a cambio de otras especies, ya en dinero), o vendida por aquél en los exiguos mercados locales. Dado que no conocemos con certeza las pérdidas en el trigo de 1808, optamos por no incluirlas en el recuento final, salvo el caso específico de Angel Raña, de quien sabemos que perdió por el incendio de su galpón toda la cosecha de 1809 y el diezmo de 1808, estimado el todo en "más de zien fanegas". ${ }^{18}$

Poseemos precios de mercado de las especies recolectadas; lo cual nos permitirá calcular aproximadamente el ingreso bruto de cada explotación. ${ }^{19}$ Para ello hemos optado por reducir a dinero (reales de plata) todo el trigo cosechado y el ganado procreado en promedio en ambos años, a fin de obte-

16 Sirvan estos ejemplos, entre muchos: "Ysidro Leys pago dos potros... Digo yo Maria Jpha. Benites y el Indio Matias que emos dado seis animales del año de 1808 y 1809. Firmo a ruego [por no saberlo hacer los contribuyentes] Juan Acensio Benites".

17 Según las fechas de los recibos respectivos, la recaudación duró desde el 6 de junio hasta el 29 de noviembre de 1809. Sabemos que hubo pérdidas (varios sacos de trigo "enteramente podrido", "agorgojado", o "inservible); pero no conocemos su monto total, aunque no parece que superaran el $30 \%$ (dado un promedio de diferencias entre lo cosechado por aquellos productores de los cuales tenemos datos desagregados de producto obtenido en 1808 y en 1809, sin incluir los casos en que esas diferencias se debieran a diversos avatares productivos, cuando fue posible conocerlos).

18 AGN, IX-20-5-7. Hemos tomado una media de producción anual de 100 fanegas de trigo para esta unidad productiva. Por su ubicación queda incluida entre las explotaciones del área 3. La fanega de trigo del este entrerriano (diferente de la del oeste), todavía en 1875 se dividía en 12 almudes y tenía un peso total de 210 a 225 libras, o sea un poco más que la fanega de trigo de Buenos Aires, que contenía de 210 a 215 libras, equivalentes a 137,198 litros del sistema métrico. Ver Napp, Ricardo: La República Argentina, Sociedad Anónima, Buenos Aires, 1876, pág. 369; también Pérez Colman: Historia ..., vol. III, pág. 23. El diezmo de 1808-9 fue recolectado enteramente en fanegas del este entrerriano.

19 "Ingreso bruto" significa aquí estrictamente el trigo cosechado y el procreo de animales registrados por los recaudadores. No contamos con datos de otros rubros productivos, así como acerca de los patrimonios completos de los productores (que podían incluir tierra, construcciones, herramientas, bienes de lujo o aun aves de corral). Los precios fueron tomados de: precios en mercados locales de las ventas de las especies recogidas; precios de compra por parte de los propios productores; valuaciones del recaudador en los casos en que se efectúan pagos de lo devengado de una especie en otra diversa (por ejemplo, diezmo de trigo pagado con terneros u ovejas). De las series obtenidas (todos los precios de cada una de las especies en cada una de las áreas) se tomó la mediana como índice para la conversión a dinero. No hay variaciones excesivamente significativas en torno a ella. 
ner una medida resumen del producto de cada explotación y la consiguiente distribución porcentual de lo producido por rubros ${ }^{20}$ Los que figuran son sin duda los más valiosos e importantes, pero no los únicos, como lo reconocía el propio recaudador, quien no fue capaz de dar cuenta del rendimiento de huertas y aves de corral por culpa de la larga y fuerte tradición evasiva local. ${ }^{21}$

\section{CUADRO I}

MEDIANAS DE PRECIOS AGRÍCOLAS EN EL NORTE ENTRERRIANO, 1808-180922

\begin{tabular}{cccccc} 
Área & Trigo & Ganado & Mulas & Potrillos & Ovejas \\
\hline 1 & 20 & 3.5 & 5.5 & 1 & 0.5 \\
2 & 24 & 4 & 6 & 0.5 & 0.5 \\
3 & 24 & 4 & 6 & 0.5 & 0.5
\end{tabular}

El valor de la producción de cada unidad de explotación será entonces la suma del valor particular de cada uno de los rubros específicos que han sido producidos en ambos años, dividida por dos (la cantidad de años con datos), a fin de trabajar con el promedio anual. Dado que no poseemos otras informaciones acerca de la estructura productiva, a los fines perseguidos aquí el valor anual de la producción será para nosotros también la medida del tamaño de la unidad productiva respectiva. El porcentaje con que cada

20 El monto del diezmo recaudado en cada especie por ambos años fue dividido por dos y luego multiplicado por diez para obtener un promedio de lo producido en cada explotación. No hay casos con desproporción muy grande entre la producción de un año y de otro. En lo que respecta al trigo, si bien el año de 1808 fue de producción mediocre y aun para nuestros cálculos se ha perdido parte de la cosecha, el de 1809 fue por el contrario abundante; por lo cual no es irrazonable esperar que el promedio de la producción de 1808 y 1809 nos dé como resultado una cifra aproximada a la de un año normal. Respecto a los precios, el relativamente largo tiempo transcurrido desde la cosecha hasta el cobro del impuesto y la venta de las especies, además de los registros de precios mínimos y máximos de la región en los años previos que se encuentran en la correspondencia cruzada entre el recaudador y los miembros de la Junta de Diezmos, nos indican que nuestras medianas de precios no están tampoco lejos de las de un año normal. Correspondencia entre el recaudador Elía y la Junta de Diezmos, 1807-1809, en AGN, IX-20-5-7, expediente caratulado "Sobre los limites que deve compreender el Remate delos Diesmos del Arroyo dela China".

21 "... Asi es, que mi hijo para coletar los granos, aves \&a. lo pudo executar con su gente, con sus carros, con cavallos propios, y con otros arbitrios que le ahorrarian gastos; pero lo cierto es, que ninguno ha tenido autoridad para recaudarlos, y esta es una licencia perniciosa, y causatiba de enredos, y diferencias...” Dn. Juan Ygnacio de Elia a los Señores de la Mesa Decimal, Buenos Aires 9 de noviembre de 1807, en AGN, IX-20-5-7.

22 Todos los precios en reales de plata; el trigo por fanegas de Concepción y los animales por cabeza. 
uno de los rubros de esa producción contribuye al valor total producido será el indicio de la orientación productiva de la explotación, y por tanto del carácter de ésta (en términos simples: agrícola, ganadera o mixta).

\section{c) Retrato de una economía de frontera: unidades de explotación y orientación productiva por áreas}

Para una aproximación inicial nos resultará útil efectuar algunas inferencias con lo que sabemos sobre el tamaño de las explotaciones, medido, como hemos dicho, según lo que ha producido cada una de ellas en los años citados. En el siguiente cuadro aparecen resumidos algunos resultados:

\section{CuAdRo II}

MEDIAS DE TAMAÑOS DE UNIDADES PRODUCTIVAS DEL NORTE ENTRERRIANO, 1808-9 (EN REALES DE PLATA)

\begin{tabular}{lrcc} 
& & \multicolumn{2}{c}{ Media alfa podada } \\
& $N$ & Media & un 5\% \\
\hline General & 155 & 1.831 & 1.561 \\
Área 1 & 77 & 1.530 & 1.136 \\
Área 2 & 45 & 2.078 & 1.862 \\
Área 3 & 33 & 2.197 & 1.251
\end{tabular}

Esta primera distribución de los tamaños nos indica ya algunos rasgos de la estructura productiva del norte entrerriano: el descenso de la media alfa podada en el área 3 muestra la existencia de grandes unidades de explotación (entre las que destacan las de Urquiza y Sagastume), rasgo regional que al parecer logrará perdurar en el tiempo, si nos atenemos al enorme tamaño que adquirirán las estancias y saladero de Justo José de Urquiza ya avanzado el siglo XIX. En el área 2, de muy reciente colonización y, según parece, con peores condiciones de explotación agrícola que el área 3, la media alfa podada desciende mucho menos que en las restantes. ${ }^{23} \mathrm{Si}$ bien allí el tamaño de las unidades según este indicador es propor-

23 Sobre las condiciones productivas del área 2, digamos que la zona que se extendía al norte del Molino, por su lejanía del mercado de Concepción y el consiguiente mayor costo del flete fluvial, se encontraba en desventaja con respecto al área 3, al sur de aquel río. 
cionalmente mayor que las otras áreas, la distancia entre las unidades más pequeñas y las más grandes es también menos fuerte, lo cual nos habla de un estadio de ocupación humana aún temprano y, quizá, de la existencia de tierras de menor calidad..$^{24} \mathrm{El}$ área 1 , en tanto, es la que cuenta con mayor número de explotaciones, y sería la más densamente poblada si prescindiéramos de la villa de Concepción; su media alfa podada desciende más que en la fronteriza área 2, pero menos que en la 3. El relativamente escaso peso de la gran unidad en esta área 1 puede estar relacionado con el hecho de que la misma se había poblado en gran parte con pastores correntinos que se desplazaron desde los campos más tradicionales de su provincia, ya algo saturados por una larga historia de más de dos siglos de ocupación. Es sugestivo que la distribución de los tamaños de las unidades productivas allí guarde cierta relación con la que hemos encontrado para los datos obrantes en una fuente muy similar a la entrerriana, una percepción del diezmo realizada en 1805 en las áreas correntinas tradicionales (el ángulo formado por el Paraná, en cuyo vértice se encuentra la ciudad de Corrientes): tratando los datos de ellas con los mismos criterios que hemos empleado aquí, la media resultante es de 1.378 reales, mientras que la media alfa podada en un 5\% alcanza los 1.036 reales de plata, esto es, un $25 \%$ menor, o sea la misma diferencia entre ambos índices que observamos para el área 1 entrerriana. ${ }^{25}$

Nuestro siguiente paso será conocer los distintos perfiles productivos de las áreas bajo análisis, valiéndonos de la orientación productiva de las unidades de explotación que las componen, para lo cual hemos optado, como ya dijimos, por agrupar a estas últimas en clusters aglomerativos jerárquicos según el porcentaje en que cada uno de los rubros respectivos contribuyó al valor total de la producción. Los clusters (se fijaron tres) fueron obtenidos por el método de Ward, es decir por cálcu-

24 Este punto aún no ha sido estudiado, pero V. Martin de Moussy apunta que el rendimiento del trigo entrerriano era de 20 granos por uno en Paraná, y de 18 en Nogoyá; en el área de Concepción del Uruguay, en tanto, el mismo sólo alcanzaba a 13. Martin de Moussy, Victor: Description Géographique et Statistique de la Confédération Argentine, Firmin Didot, Paris, 1860-64, vol. I, págs. 474-5. El insigne sociólogo Max Weber (sí, el de la ética protestante) consideraba "medio", hacia 1892, un rendimiento de 20 por uno en el área de La Paz, cerca del Guayquiraró. Véase Weber, Max: "Empresas rurales de colonos argentinos" reproducido en Ruralia, 6, FLACSO, Buenos Aires, 1995, pág. 125 .

25 Datos de productores correntinos de 1805 en AGN, IX-20-5-7. Se trata de 312 productores con datos de procreo vacuno, equino y ovino. Una semejanza tan estrecha puede no ser más que una casualidad; sin embargo, otros indicios cualitativos la apoyan. No nos dedicaremos a ellos aquí por razones de espacio. 
lo de distancias al centroide elevadas al cuadrado, y midiendo luego el incremento de las mismas. ${ }^{26}$

\author{
CUADRO III \\ AGRUPACIÓN EN CLUSTERS DE UNIDADES PRODUCTIVAS \\ DEL NORTE ENTRERRIANO, 1808-1809, SEGÚN EL PORCENTAJE \\ DE CADA UNO DE LOS RUBROS INVOLUCRADOS
}

\begin{tabular}{lrrccccc} 
& & \multicolumn{6}{c}{ Medias $^{27}$} \\
\cline { 3 - 8 } & $N$ & Tamaño & Vacunos & Mulares & Equinos & Trigo & Ovinos \\
\hline General & 155 & $1.831,22$ & 0,7250 & 0,0034 & 0,0290 & 0,2094 & 0,0332 \\
& & & & & & & \\
Cluster 1 & 25 & $1.135,70$ & 0,6437 & 0,0170 & 0,0941 & 0,0725 & 0,1727 \\
Cluster 2 & 100 & $2.367,31$ & 0,9609 & 0,0011 & 0,0211 & 0,0098 & 0,0072 \\
Cluster 3 & 30 & 623,83 & 0,0066 & - & 0,0009 & 0,9889 & 0,0035
\end{tabular}

Puede verse que los clusters resultantes determinaron la agrupación de las distintas unidades productivas en torno a perfiles de rasgos bastante definidos: el primer cluster para las explotaciones mixtas (predominio del ganado vacuno, pero con presencia no despreciable de otros rubros, en especial ovinos); el segundo para las explotaciones dedicadas casi exclusivamente al ganado vacuno; y el tercero para las agrícolas, o trigueras. $\mathrm{La}$ media de valor de las explotaciones del segundo cluster es mayor que en los otros dos, lo que nos reafirma el carácter de frontera ganadera de la región. Es altamente probable que, aun en el caso en que hubiéramos contado con los datos completos del trigo de 1808, los mismos no hubieran variado significativamente la situación global. ${ }^{28}$

26 Dado que trabajamos con las proporciones de cada variable sobre el output total de cada unidad productiva y deseamos que los resultados reflejen los pesos relativos de cada una para definir en forma más clara los perfiles productivos individuales, los valores de cada variable no fueron estandarizados.

27 Tamaño: media de la suma total del valor de la producción, según criterio descripto anteriormente, en reales de plata. Resto de los rubros en proporción sobre el total del valor producido (1).

28 Como tampoco la varió el inexorable paso del tiempo: en 1926, las estadísticas daban para el departamento de La Paz (que incluía el viejo Guayquiraró) un stock vacuno de 316.335 cabezas, y para el de Concordia (fundado sobre las tierras alrededor del Yeruá) uno de 301.844, siendo ambos el tercero y el cuarto de la provincia (después del de Gualeguaychú), con una media respectiva de 9.87 y 4.82 cabezas por habitante. Ver Nágera, Juan José: Atlas de Entre Rios, Colombatti, Buenos Aires, 1928. 
Pero, si bien ese predominio abrumador del ganado vacuno nos indica que el valor económico allí estaba en directa relación con la posesión del mismo, existe sin embargo un $16,13 \%$ de unidades de producción mixtas y un $19,35 \%$ de agrícolas, cuya presencia no es homogénea si prestamos atención a la distribución espacial de las mismas:

\section{CUADRO IV}

DISTRIBUCIÓN DE LAS UNIDADES PRODUCTIVAS

DEL NORTE ENTRERRIANO, 1808-9, SEGÚN LOS CLUSTERS

Y ÁREAS EN QUE SE AGRUPAN

\begin{tabular}{lcccc} 
& Cluster 1 & Cluster 2 & Cluster 3 & TOTALES \\
\hline Area 1 & 22 & 52 & 3 & 77 \\
Area 2 & 1 & 37 & 7 & 45 \\
Area 3 & 2 & 11 & 20 & 33 \\
\hline TOTALES & 25 & 100 & 30 & 155
\end{tabular}

En efecto, vemos que la mayoría de las unidades productivas que figuran en el primer cluster (mixtas) se concentra en el área 1 (22, o sea el 88\% del total); las del segundo (que correspondería a las unidades ganaderas) se distribuyen mayormente entre las áreas 1 y 2 , con predominio en la primera (52 y 37, o 52\% y 37\% del total); y por último, las unidades correspondientes al tercer cluster (agrícolas) se concentran en el área 3 (20, o el 67\% del total). De esta manera, podemos intuir que el perfil productivo de cada área es distinto, y que la técnica de clusters adoptada nos ayuda a conocerlo mejor.

Podemos apoyar esta imagen con la información cualitativa. El área 1 , que concentra casi todas las unidades de producción mixtas que hemos identificado, es la más cercana a Corrientes, en la que, según los datos del diezmo de 1805 y algunos trabajos de investigación, la cría comercial del ovino estaba bastante extendida, condiciones que parecen reproducirse en las tierras entrerrianas de allende el Guayquiraró. ${ }^{29}$ Sin embargo, el hecho

29 En el diezmo de 1805 un $23 \%$ de las unidades de explotación posee ovejas, siendo en buena parte de ellas la mayor porción del valor. Es de destacar que probablemente, dada la circunstancia de que el pago del impuesto se efectuó en cueros vacunos y no en plata, una cantidad desconocida de los productores que entregan unos pocos cueros de vaca estén cancelando con ellos una porción no declarada en forma explícita de su procreo de ovinos, ya que el ínfimo precio de éstos no representaba 
de que predominen allí las explotaciones ganaderas (como vemos, en el área 1 se ubica más de la mitad de las explotaciones que resultaron agrupadas en el segundo cluster) nos sugiere que las semejanzas iban un poco más allá: el variable auge que al finalizar la época colonial experimentaron las exportaciones de cueros correntinos hacia Buenos Aires tenía su secreto origen en la ganadería extensiva practicada en la amplia franja delimitada por los ríos Santa Lucía y Corrientes, así como en las difusas estancias de ganado semisalvaje de las planicies del Payubre, separadas por pocas leguas del Guayquiraró; esa perdurable mezcla de tradiciones productivas y condiciones de frontera, esa convivencia pacífica entre rebaños ovinos y vacunos nos sugiere que el límite entre ambas jurisdicciones (que ciertas convenciones habían atribuido a aquel río) no constituía más que una división negociada de espacios de poder, ya que pareciera que, con su gente, los correntinos que colonizaron el norte entrerriano hubieran llevado consigo no sólo parte de su cultura y de su sociedad, sino también de su economía. ${ }^{30}$

El área 2, en cambio, nos muestra un perfil de decisivo predominio de ganadería vacuna: se trata, como hemos visto, de un área de poblamiento muy reciente, que acusa quizá la influencia de la tradición ganadera de Yapeyú, la "dehesa de las misiones"; en cualquier caso, esa casi totalidad de unidades de explotación orientadas al vacuno es un claro indicio de una sociedad más basta, más nueva, más simple; una suerte de frontera dentro de la frontera. En medio de una ocupación humana sumaria, se adivina que esos rebaños vacunos ampliamente dominantes constituían tanto un activo de inversión como un bien mueble fácilmente transportable ante las a menudo peligrosas circunstancias del lugar, que había sufrido los avatares de una guerra con Portugal hacía apenas siete años, y que no tardaría en volver a padecerla, aumentada, pocos años más tarde. Esa extensa área semivacía conservaría su carácter de frontera aún durante bastante tiempo,

\footnotetext{
sino una parte muy menor de aquéllos. Chiaramonte ha destacado la abundante producción textil correntina de inicios del siglo XIX (cuyos ponchos habían ganado merecida fama en todo el litoral), basada en el algodón pero también en la lana proveniente de los extensos planteles ovinos locales. Chiaramonte, José Carlos: Mercaderes del litoral. Economía y sociedad en la provincia de Corrientes, primera mitad del siglo XIX. Fondo de Cultura Económica, Buenos Aires, 1991, pág. 65.

30 Sobre el ambiente geográfico y económico de la actual provincia de Corrientes a inicios del siglo XIX, véase la magistral descripción de Chiaramonte: Mercaderes del litoral...; también Maeder, Ernesto: Historia económica de Corrientes en el periodo virreinal, Academia Nacional de la Historia, Buenos Aires, 1981, págs. 50 y ss.; una visión general acerca del auge de la ganadería correntina a fines de la era colonial en Whigham, Thomas: "Cattle Raising in the Argentine Northeast. Corrientes c. 17801870" en Journal of Latin American Studies, 20, 1988.
} 
ya que tardaría todavía dos décadas en lograr albergar un humilde caserío llamado algún día a convertirse en la ciudad de Concordia. Allí, no obstante, se habían ya sentado las bases de una modesta prosperidad que constituye un paradigma de lo mucho que podía esperarse de esas tierras vírgenes y de esa economía construida con elementos sumarios, cuya misma simplicidad y abundancia hacían parecer inagotables. Una prosperidad modesta, hija tanto de la mayor distancia que separaba esta área de los mercados ultramarinos como de recursos más magros y costos de transporte más altos que los disponibles para las grandes estancias situadas más al sur, que sin embargo quemaría con avidez las etapas evolutivas de una expansión ganadera que ya tenía su historia en otras regiones no demasiado lejanas, y que es además un buen ejemplo de las limitaciones que podía encontrar esa expansión.

El área 3, nuevamente distinta, nos ofrece una imagen marcada por la presencia de un vigoroso mercado urbano regional, aunque de dimensiones modestísimas si lo comparamos con otros: la futura ciudad de Concepción del Uruguay, que, una década después, alcanzaría a tener más de 1.200 habitantes, por lo que puede admitirse que en 1808 ya constituía una población de cierta envergadura. ${ }^{31}$ En todo caso, esa aldea sobria y decente justificaba un consumo de trigo que, en un efecto que recuerda el de los "círculos de Von Thünen", determinó el perfil de las unidades productivas de las cercanías: como podemos ver en el cuadro, la mayor parte de ellas son agrícolas. ${ }^{32}$ Es además verosímil que Concepción constituyera un mercado triguero no sólo para la producción inmediata sino también para la de otras zonas algo más lejanas. ${ }^{33}$

31 Datos del censo de 1820 cedidos gentilmente por R. Schmit. Sobre el crecimiento poblacional del oriente entrerriano entre 1820 y 1849 ver Schmit: "Población, migración...".

32 Sobre los "círculos de Von Thünen", véase Hall, Peter (editor): Von Thünen's "Isolated State": An English Edition, Pargamon, New York, 1966, citado en Garavaglia, Juan Carlos: "Un siglo de estancias en la campaña de Buenos Aires: 1751 a 1853", en Hispanic American Historical Review, 79-4, Duke, 1999, pág. 720, en donde se efectúa una útil aplicación de ese modelo al mercado urbano de Buenos Aires y sus cercanías.

33 Un ejemplo quizá podría dar la pauta: en 1788, don Timotheo Alvarez Campana, pulpero en Concepción, acusaba recibo de 53 fanegas de trigo y 2 de maíz que le habían sido enviadas a consignación desde Gualeguay; las ventas del mismo no eran sin embargo muy entusiastas, ya que "en este destino [Concepción] hasta el presente no Estante de haver hecho dar la vos qe. se bendia y el presio arreglado aloqe. Vmd. en las suyas me previene; nadie ha aparecido a comprar una quartilla..." Timotheo Alvarez Campana a Dn. Lorenzo Javalera, Concepción del Uruguay, 24 de octubre de 1788, en AGN, IX-33-6-5, Hacienda, 55, 1417, fs. 1 r. y v. Las alternativas de las cosechas y de los precios locales sin dudas determinaban variaciones fuertes en el comercio del trigo. 


\section{d) Diferencias en el volumen producido, diferencias en el valor y en la orientación de la producción}

Si bien no contamos con datos acerca de la propiedad de la tierra ni la posición social de la mayoría de los actores, así como tampoco sobre la posibilidad de que alguno de ellos pudiera poseer inversiones importantes en otros rubros de la economía local (por ejemplo en el comercio) o aun en otras jurisdicciones, es probable que, de cualquier manera, las diferencias en el valor medio del producto de las explotaciones nos permitan inferir en forma bastante cercana algunos rasgos de la distribución de los recursos, habida cuenta de que los datos con que contamos reflejan las actividades económicas dominantes y algunas de las vías más comunes de acumulación de riqueza de esa época y lugar.

En principio podemos decir que las diferencias en el volumen de recursos manejados eran al parecer bastante marcadas. Aquellas explotaciones con valor producido menor o igual a 2.000 reales de plata tienen una media general de 759 reales; por el contrario, las de valor mayor a 2.000 reales tienen una media de 6.646, esto es, más de diez veces más. En otro trabajo hemos comparado los datos de stock de vacunos del norte entrerriano con los correspondientes a otras regiones del Río de la Plata de fines del siglo XVIII e inicios del XIX, y los resultados nos indican que la distribución de la riqueza pecuaria era bastante más regresiva en Entre Ríos que en las demás: si quienes sólo poseían hasta 500 cabezas de ganado vacuno formaban a menudo las dos terceras partes o más de los productores en Colonia (Banda Oriental), Corrientes y Rio Grande do Sul, y poseían hasta el $31 \%$ del rebaño total, en Entre Ríos el mismo segmento abarcaba al 54\% del total de los productores, pero apenas daba cuenta del 5\% del rebaño vacuno. ${ }^{34}$ Consecuencia directa de ello, el sector más pudiente (más de 1.999 cabezas por unidad productiva) dominaba en Entre Ríos al $72 \%$ de la riqueza pecuaria total en vacunos; mientras que en Colonia era dueño del $60 \%$, en Rio Grande do Sul del $42 \%$ y por fin en Corrientes, al parecer la más cercana a los bellos sueños de justa distribución del capital

34 Respectivamente, en Corrientes (datos de 1805) quienes poseían hasta 500 vacas sumaban el $82 \%$ de los propietarios y poseían el $31 \%$ del stock vacuno; en Rio Grande do Sul (datos de 1784) eran el $87 \%$ de los productores y poseían el $27 \%$ del stock, y en Colonia, Banda Oriental (datos de 1796) el $73 \%$, y poseían el $18 \%$ del stock. Ver nuestro trabajo citado en la nota siguiente. 
que preconizaban por entonces ciertos filósofos sociales, ese mismo segmento sólo poseía el $29 \%$ de la fortuna vacuna local. ${ }^{35}$

\section{CUAdro Va}

UNIDADES DE EXPLOTACIÓN DEL NORTE ENTRERRIANO, 1808-9, CON PRODUCCIÓN ANUAL MENOR O IGUAL A 2.000 REALES DE PLATA ${ }^{36}$

\begin{tabular}{lccccccc} 
& & \multicolumn{7}{c}{ Medias } \\
\cline { 3 - 8 } & $N$ & Tamaño & Ganado & Mulas & Potrillos & Trigo & Ovejas \\
\hline General & 123 & 578,7 & 0,7004 & 0,0005 & 0,0324 & 0,2305 & 0,0363 \\
& & & & & & & \\
Cluster 1 & 20 & 753,7 & 0,6366 & 0,0028 & 0,1098 & 0,0573 & 0,1934 \\
Cluster 2 & 76 & 605,7 & 0,9634 & - & 0,0231 & 0,0070 & 0,0065 \\
Cluster 3 & 27 & 373,1 & 0,0074 & - & 0,0011 & 0,9877 & 0,0039
\end{tabular}

\section{CUADRo $\mathrm{Vb}$}

UNIDADES DE EXPLOTACIÓN DEL NORTE ENTRERRIANO, 1808-9, CON PRODUCCIÓN ANUAL MAYOR A 2.000 REALES DE PLATA

\begin{tabular}{lrcccccc} 
& & \multicolumn{7}{c}{ Medias } \\
\cline { 3 - 8 } & $N$ & Tamaño & Ganado & Mulas & Potrillos & Trigo & Ovejas \\
\hline General & 32 & $6.645,6$ & 0,8197 & 0,0149 & 0,0158 & 0,1284 & 0,0211 \\
& & & & & & & \\
Cluster 1 & 5 & $2.663,5$ & 0,6721 & 0,0740 & 0,0312 & 0,1330 & 0,0897 \\
Cluster 2 & 24 & $7.945,9$ & 0,9529 & 0,0045 & 0,0146 & 0,0185 & 0,0095 \\
Cluster 3 & 3 & $2.880,0$ & - & - & - & 1,0000 & -
\end{tabular}

35 Las fuentes son los registros de percepción del diezmo correntino y entrerriano que hemos utilizado aquí, y censos agrarios para los casos de Rio Grande y Colonia. Se efectuó también una comparación con una muestra de inventarios de Buenos Aires trabajada por Juan Carlos Garavaglia. La diversidad de las fuentes y de las regiones no impidió obtener resultados verosímiles. Ver los datos y el análisis en Djenderedjian, Julio: “¿Un aire de familia? Producción agrícola y mercados desde Corrientes y Entre Ríos a Rio Grande do Sul, fines del siglo XVIII y comienzos del XIX: algunas reflexiones comparativas", ponencia presentada en las Primeiras Jornadas de História Regional Comparada, Porto Alegre, 23 al 25 de agosto de 2000.

36 Recordamos que el cluster 1 agrupa a las unidades mixtas; el 2 a las ganaderas y el 3 a las agrícolas. 
Entre los productores cuyo output anual ha sido menor a 2.000 reales, podemos advertir que las medias del valor de las unidades de explotación mixtas y ganaderas (esto es, las agrupadas en los clusters 1 y 2) se acercan mucho: respectivamente, son de 753.7 y 605.7 reales. Por el contrario, si las confrontamos con las explotaciones cuyo valor de producción anual fue superior a 2.000 reales, veremos que la media del valor de las unidades productivas ganaderas es en ellas mucho más importante y sólido que en las trigueras y mixtas: con 7.946 reales, prácticamente triplican los de éstas, de 2.880 y 2.663 respectivamente ${ }^{37} \mathrm{Si}$ bien una medición así resulta algo tosca, la orientación ganadera de las unidades de explotación mayor es un hecho incontestable, que confirman por otra parte algunos testimonios cualitativos y que está muy de acuerdo con los rindes decrecientes del cultivo de trigo a medida que se echa mano de trabajo comprado. ${ }^{38}$ Es muy probable que, tal como ocurría en el Gualeguay de la misma época, las necesidades de grano de esas grandes explotaciones fueran suplidas por el mercado, al menos en su mayor parte. ${ }^{39}$ Volviendo sin embargo a nuestros datos, todo parece indicar que las unidades menores se orientan a una diversificación de actividades que, si bien no es necesariamente exclusiva, sí las diferencia mucho de la especialización ganadera que caracteriza a la mayor parte de las unidades productivas más grandes. Esta especialización podría muy bien deberse al deseo de optimizar recursos escasos (en especial la mano de obra, que por otra parte todo indica era de lejos el componente más importante del costo de producción en las grandes estancias) concentrándolos en una actividad comercialmente más rentable, si recordamos que tanto el valor agregado como los costos de producción serían en la cría del vacuno menos intensivos en mano de obra que en la producción

37 Es de notar que aun si descartamos las grandes estancias de Sagastume y Urquiza la diferencia de valor en favor de las unidades productivas ganaderas se mantiene: la media general de éstas sin contar aquellos dos casos outliners alcanza a 1.899 reales de plata; esto es, más de un $67 \%$ superior a la media de las unidades mixtas, que sólo llega a los 1.136 reales.

38 El Administrador General de las Temporalidades de Corrientes manifestaba su aprobación al mayordomo de la gran estancia del Rincón de Luna por el despido de unos peones chacareros, "por no estar pagando tantos sueldos superfluos", agregando que en "el cuidado delas haziendas [...] es endonde deven poner toda atenzion, y quitar los chacareros por nodar probecho ninguno ...”. Jph. Fernandez Blanco a Jose de Aguirre, Corrientes, 9 de noviembre de 1777, en AGN, IX-22-6-6, Temporalidades de Corrientes, 2, expediente caratulado "Cincuenta y ocho documentos...", sin foliar.

39 El libro de una pulpería de Gualeguay de los años 1808-1810 muestra largas cuentas corrientes de al menos un gran estanciero, Juan Castares, y su mayordomo, en las cuales la compra de alimentos y bebidas para el personal ocupan la mayor parte, así como las compras de pan a ciertas personas que son claramente pequeños productores. Libro de cuentas de un comercio de ramos generales (identificado por nosotros como perteneciente a una pulpería de Gualeguay) en AGN, IX-12-6-5. 
triguera y que en la de ovinos, aun cuando estamos todavía muy lejos de los niveles de especialización y refinamiento que requerirán estos últimos a mediados del siglo XIX.$^{40}$ Por lo demás, ¿sería excesivo inducir que esas otras explotaciones que producían valor anual menor a 2.000 reales eran mayormente manejadas por pastores y labradores que recurrían sobre todo a mano de obra de bajo costo de oportunidad, esto es, reclutada en el seno de la propia familia, y que por lo tanto podían encarar actividades que quedaban fuera de las posibilidades de las explotaciones grandes, en razón de ese costo mayor que implicaba el tener que recurrir a mano de obra comprada? ${ }^{41} \mathrm{Si}$ admitiéramos esto, tendríamos que, si bien la presencia de un mercado consumidor (en nuestro caso la villa de Concepción) podía definir la orientación productiva de las unidades de explotación situadas en sus inmediaciones, en las áreas en que esta presencia distorsionante no se hacía sentir probablemente las razones de la dedicación a la agricultura o a la producción mixta antes que a la ganadería habría que buscarlas en la particular estructura de costos diferenciales que depende del grado de uso de mano de obra asalariada. En otras palabras, que a mayor uso de este factor por parte de una unidad de explotación determinada, correspondería una más decidida orientación a la producción ganadera. No nos es posible por el momento verificar esta hipótesis, pero luego volveremos sobre el tema. ${ }^{42}$

40 Estudios efectuados sobre estancias bonaerenses y entrerrianas indican que la mano de obra ocupaba alrededor del $40 \%$ de los costos de producción en las mismas. Ver por ejemplo las cuentas de la estancia de Pedro García de Zúñiga, 1800-1804, en AGN, Sucesiones, 5899. Sobre la campaña de Buenos Aires la bibliografía es abundante; entre lo más reciente puede citarse Amaral, Samuel: The Rise of Capitalism on the Pampas. The Estancias of Buenos Aires, 1785-1870, Cambridge University Press, Cambridge, 1998. El cuidado de las ovejas era mucho más exigente que el del ganado mayor, y por tanto es comprensible la tendencia de los pequeños pastores a su cría, dada su mayor disponibilidad de mano de obra familiar. Un excelente relato de época acerca de los cuidados que demandaba la cría de ovejas en el litoral colonial en Dobrizhoffer, Martín: An Account of the Abipones, an Equestrian People of Paraguay, John Murray, London, 1822, vol. I, págs. 246/7.

41 Jorge Gelman ha llamado la atención acerca de las condiciones diferenciales de la producción triguera en chacras mercantiles y en unidades de producción campesinas en la región de Colonia, en la Banda Oriental, acotando que estas últimas, en razón de la disponibilidad de mano de obra familiar, se encontraban en mejores condiciones de afrontar los costos de producción de la agricultura que las grandes unidades de explotación, que debían recurrir a mano de obra asalariada. Ver Gelman, Jorge: Campesinos y estancieros. Una región del Río de la Plata a fines de la época colonial, Los Libros del Riel, Buenos Aires, 1998, especialmente págs. 231 y ss.

42 El cálculo de los costos de producción en unidades de explotación campesinas en el Entre Ríos colonial se hace particularmente dificultoso, en especial por la falta de estudios demográficos integrales y por la baja calidad de los censos de la época; aunque podríamos estimar razonablemente los costos de manutención de una familia campesina allí, es por el momento muy aleatorio determinar la cantidad promedio de miembros económicamente activos en ella, así como relacionar ese dato con el rebaño; por otra parte, las variaciones regionales parecen haber sido bastante marcadas. En lo que res- 
Otro aspecto interesante para reflexionar acerca de las diferencias de tamaño reside en la porción del mercado local que eventualmente controlarían los grandes productores. Si bien en el caso del vacuno es poco probable que esa influencia pudiera perjudicar a las demás explotaciones, dado que los grandes estancieros venderían sus cueros directamente en Buenos Aires, mientras que los pequeños y medianos productores se valdrían de toda la red de intermediarios y pulperos con quienes mantendrían usualmente lazos de endeudamiento, hipotéticamente no ocurriría lo mismo en lo que hace al mercado del trigo, ya que el único lugar de realización local del mismo era la villa de Concepción, y es muy poco probable que existieran exportaciones de cereal a Buenos Aires u otras plazas importantes, ya que las mismas se hallaban abastecidas por su propio hinterland y, salvo casos excepcionales, los precios allí no justificaban los costos de transporte que hubieran debido pagar los productores entrerrianos..$^{43}$

Pasemos entonces al análisis de esas circunstancias, teniendo presente lo anterior. En principio, si bien la concentración se muestra mayor en la producción ganadera, con el $10 \%$ de las unidades productivas de mayor tamaño controlando el 59\% del stock, mientras que entre las agrícolas ese mismo segmento sólo es dueño del $46 \%$ del total del trigo cosechado, al acercarnos un poco más sutilmente a esos pobres datos advertimos que las grandes unidades agrícolas podían llegar a incursionar con más firmeza en

pecta a las grandes unidades de producción, la estructura de costos y el nivel salarial parecen acercarse a los de Buenos Aires en el área sudoriental de la ulterior provincia, esto es, la zona de Gualeguaychú y Gualeguay. En cambio, en el área noroccidental ambos factores son mucho más similares a lo que sabemos de las grandes estancias correntinas, con salarios nominales más bajos, una parte de los cuales se pagaba en efectos y abundante uso de diversas "monedas de la tierra", mientras que en el sur los mismos se pagaban mayormente en efectivo, y eran más altos.

43 Para un funcionario experimentado en temas agrícolas como Nicolás del Campo, tanto el trigo cosechado en Buenos Aires como en "la otra banda" (Entre Ríos) "ni aqui, ni allá tiene extracción”. Si bien luego de las guerras de la independencia las cosas cambiarían, ya que D’Orbigny pudo constatar que en el área del Paraná se producía trigo "que se lleva a Buenos Aires", el único caso que hemos encontrado al respecto para los años coloniales data de 1773, tiempos de una gran sequía en Buenos Aires. A pesar de las ventajas que se ofrecían, sin embargo la operación no se concretó, lo que indica que el consumo local absorbía por entero la producción. Ver AGN, IX-3-5-6, Correspondencias de Entre Ríos, 1, 1722-1792, [Vértiz] a González, Buenos Aires, 7 de febrero de 1773, y González a Vértiz, Gualeguaychú, 7 de marzo de 1773. El dictamen de Nicolás del Campo, fechado en Buenos Aires, 8 de agosto de 1808, en AGN, IX-20-5-7, “Sobre los limites ...”. D’Orbigny, Alcides: Viaje a la América meridional; Brasil, República del Uruguay, República Argentina, la Patagonia, República de Chile... Realizado de 1826 a 1833, Futuro, Buenos Aires, 1945, vol. I, pág. 403. Sobre el endeudamiento de los productores menores, véase Djenderedjian, Julio: "Buenos negocios en tiempo de guerra: el comercio de cueros en el litoral según las cuentas de Cipriano de Urquiza, 1816-1820", en Anuario IEHS, 17, Tandil, 2002, en prensa. 
el mercado local de lo que pudieran haber logrado las ganaderas, y probablemente determinaban las tendencias de precios en razón misma de su volumen de producción. En efecto, tan sólo las tres explotaciones que más trigo han producido (Agustín Fernández, Francisco Gallego y Lorenzo López) han cosechado 720 fanegas en total en 1808-9, monto que corresponde a más del $51 \%$ del total producido por todas las unidades productivas agrícolas del área $3{ }^{44} \mathrm{Si}$ esas tres unidades mayores vendían su trigo en Concepción (y nada nos indica que no lo hicieran), eran dueñas de arbitrar los precios del cereal allí, ya que es probable que, dado su nivel productivo, contaran con depósitos o silos que les permitirían almacenar el grano hasta el momento adecuado, cosa que quizá estaba lejos de las posibilidades de los campesinos medios o pequeños. ${ }^{45}$

Esos grandes productores trigueros no son productores ganaderos. ${ }^{46}$ La especialización productiva, así como el hecho de que todos se ubiquen en las inmediaciones de la villa, refuerzan la impresión de que el control que podían ejercer sobre el mercado local del trigo podía llegar a ser importante. Sin embargo, parece claro que sólo en determinadas circunstancias las grandes explotaciones se dedican al trigo; y, por algunos casos aislados, pareciera ser que en ellas la producción de cereales era complementaria de otras actividades, y los capitales invertidos en ella quizá menores que en las restantes. ${ }^{47}$

44 El promedio anual de los tres es de 360 fanegas.

45 Hemos nombrado a Angel Raña, quien poseía 100 fanegas en un galpón en 1809. Nótese que cuenta con un depósito ad hoc a pesar de no ser uno de los productores mayores. Es probable que los pequeños y medianos productores de trigo entrerrianos estuvieran endeudados al tiempo de la cosecha, pagando con la misma esas deudas; así lo da a entender un protagonista de la época: "Señor mio. Suplico a v. sesirba favoreserme, con 23 ps. para la recojida de mi trigo, y poder con hello dar a v. una completa satyfacion, pues de 40 ps. que tenia solo me han quedado 18; de suerte que no puedo echar mano hasta no completar el dinero que me persuado ser suficiente, y espero de v. no saldra desconsolado este su afecto y sgo. servr. q.b.s.m...” Jose Antonio Hernández y Quiroga a Cipriano de Urquiza, sin lugar, pero alrededores de Concepción, 26 de diciembre de 1819. En AGN, VII-1463, Archivo Urquiza, I, fs. 168 r. y v.

46 La excepción es Angel Raña, cuyo procreo de vacunos de los años 1808-9 promedia las 730 cabezas. Igualmente, debemos considerar que los otros productores trigueros podían poseer inversiones en otros rubros de la economía local; por ejemplo Lorenzo López, uno de los más importantes, a quien nos referiremos en la nota siguiente.

47 Contamos con algunos datos sobre el mayor productor triguero de Concepción colonial, Lorenzo López, quien poseía una herrería y una pulpería importante, así como algunos esclavos. Encarna bastante bien un tipo de notable local muy frecuente en el litoral, con intereses diversificados en el comercio, la ganadería, la agricultura, y que además ejercía a menudo cargos políticos y oficiaba como prestamista. 
Otro aspecto interesante a destacar tiene que ver con la producción de mulares. Si volvemos por un momento a los cuadros $\mathrm{Va} \mathrm{y} \mathrm{Vb}$, comprobaremos que la presencia de mulas es mucho mayor en las unidades de explotación con valor de producción superior a 2.000 reales que en las de menos de esa cifra. Esto es especialmente visible en las áreas 2 y 3 , es decir aquella con frente al río Uruguay, lo cual puede deberse a que parte de la producción mercantil de esos animales se dirigía hacia el Brasil, donde la feria de Sorocaba, en las inmediaciones de San Pablo, constituía un ascendente emporio de negociación de mulares que acababan sus trabajosos días en el laboreo de los socavones de Minas Gerais. ${ }^{48}$ Dadas las complicaciones que podía significar este comercio por sus altos costos y riesgos (las fronteras no siempre estaban abiertas y a menudo alguno de los involucrados en el tráfico es acusado de contrabando), parece probable que las únicas en condiciones de encararlo en una escala lucrativa podían ser las explotaciones mayores. El mercado brasileño era sin duda mucho más inestable y poco asentado que el tradicional de las ferias de Salta y las minas de Potosí; pero, a la vez, debía asegurar ganancias más sustanciosas. ${ }^{49}$

Podemos observar asimismo, entre las explotaciones con valor de producción de hasta 2.000 reales y las de más de esa cifra, un descenso en el porcentaje de equinos y, más interesante aún, que éste es más fuerte entre las explotaciones mixtas que entre las ganaderas. Es difícil explicar esta circunstancia, ya que lo ideal hubiera sido esperar que la proporción de caballos aumentase con la proporción de ganado vacuno, puesto que ambos estaban relacionados en razón de las necesidades de montura para el control del vacuno. Una posible explicación es que, aun cuando a mayor presencia de vacunos aumenta la existencia de equinos, la proporción de aumento de éstos es menor (y por tanto el porcentaje de los mismos sobre

48 Tampoco existen aún, que sepamos, trabajos específicos sobre este punto; puede consultarse sin embargo, por sus muy útiles sugerencias, Sánchez Albornoz, Nicolás: "La saca de mulas de Salta al Perú, 1778-1808" en Anuario de la Universidad Nacional del Litoral, I, Rosario, 1965.

49 Sobre la actividad de Candioti, véase Cornejo, Florencia: "El litoral, Salta y el Perú, unidos por una compañía de mulas (Olavegoya-Candiotti), 1798-1810", en Boletín del Instituto San Felipe y Santiago, IX-31, Salta, 1980, págs. 101-113. Félix de Azara se asombraba en 1790 de los altos precios que podían conseguirse en el Brasil por el ganado rioplatense: “ ...un caballo o mula vale en el Paraguay tres o cuatro pesos, y en dichos minerales [de los portugueses en Minas Gerais] ciento." Azara, Félix de: Descripción general del Paraguay, Alianza, Madrid, 1990, pág. 74. Recordemos sin embargo que el tráfico con el Brasil estuvo muy a menudo en manos de contrabandistas, dada la esporádica situación de guerra, los imperativos políticos y los malentendidos diplomáticos entre ambas coronas, que afectaron al comercio fronterizo entre las décadas de 1780 y 1810 . 
el total del producto también lo es), dado que los rodeos son mayores y utilizan menos mano de obra por cabeza y por ende menos caballos..$^{50}$ Otra explicación, no contradictoria con esta, es que en las grandes estancias buena parte de la contratación de mano de obra recayera sobre los varones adultos de las explotaciones menores de las cercanías, quienes fueran contratados para trabajar en sus propios caballos, a fin de ganar algo más que los peones que utilizaban los caballos de la estancia, y quizá conviniéndole a ésta para evitar el mantenimiento de planteles equinos extensos. Esta práctica está documentada para la estancia de Las Garzas, en el sur correntino. ${ }^{51}$ Además, las monturas que, en las explotaciones de menos de 2.000 reales de producto anual, representan un porcentaje relativamente alto del valor total, en las grandes pierden significatividad en forma más drástica por el simple aumento de los otros rubros, en especial el ganado vacuno: en estas grandes estancias una parte significativa del plantel ganadero se encontraba alzado, lo que nos recuerda la imposibilidad cotidiana de vigilarlo, dada una muy probable escasez de brazos, que quizá se manifestaba tangencialmente en ese descenso en la presencia del equino. ${ }^{52}$ En cuanto a las explotaciones agrícolas y mixtas, debemos recordar que los bueyes constituían la principal tracción animal, tanto para el arado como para el transporte en carretas, por lo que es probable que en ellas la importancia decreciente del equino manifieste que el rebaño vacuno estaba compuesto en buena parte por animales de corral y de tiro (lecheras, bueyes, etc.), es decir que no necesitaba ser puesto a rodeo con regularidad, con gasto de peones y caballos, como ocurría en las unidades grandes con el ganado

50 Jorge Gelman ha puesto de relieve la circunstancia de que se requería prácticamente la misma cantidad de peones para un rodeo de 5.000 vacunos que para uno de 1.000 ó 2.000 , siendo la primera de esas cifras la ideal. Esto implicaba que la proporción de costos fijos en mano de obra aumentaba si disminuía el stock, o, lo que es lo mismo, que las explotaciones ganaderas más pequeñas eran menos rentables, en especial si empleaban mano de obra asalariada. Ver Gelman: Campesinos y estancieros..., pág. 187; págs. 200 y ss. Resultan interesantes los estudios de Gelman al respecto, ya que fueron realizados sobre una región (Colonia, en la Banda Oriental) de características productivas bastante similares a las del norte entrerriano, aun cuando poblada desde más antiguo.

51 Ver Djenderedjian: "Economía productiva...". Dado asimismo que el precio del ganado equino en el Guayquiraró era sensiblemente mayor que en el área oriental de la provincia, podemos intuir que quizá se hubiera dado en estos años una liquidación de stocks por parte de las unidades mayores, cuyas causas por el momento se nos escapan.

52 No existen estadísticas al respecto para Concepción; pero en la estancia del Potrero, perteneciente al Dr. Don Pedro García de Zúñiga, y que se encontraba al norte de Gualeguaychú, y cercana a Concepción, se inventariaron en noviembre de 1800 un total de 23.400 cabezas de ganado vacuno alzado, es decir más del 70\% del total (33.209 cabezas). Ver AGN, Sucesiones, 5899, "Quaderno 1ro. de la testamentaria...". No es más que un ejemplo entre muchos. 
alzado y aun con el manso..$^{53}$ Todo este análisis reclama una confirmación a través de, por ejemplo, graficar la distribución de los datos en curvas de dispersión; prescindimos de ello aquí por razones de espacio.

Para percibir las diferencias en la distribución de la riqueza entre las distintas explotaciones de una manera un poco más detallada de lo que ha sido posible con la división en "pequeñas" y "grandes" que empleamos antes, y también para estudiar las distintas gradaciones que operaban en el tamaño de las mismas, tenemos aquí los datos de producción agraria distribuidos en curvas de Lorenz.

\section{GRÁFICO I}

\section{EXPLOTACIONES Y PRODUCCIÓN AGRARIA \\ EN EL NORTE ENTRERRIANO, 1808-1809}

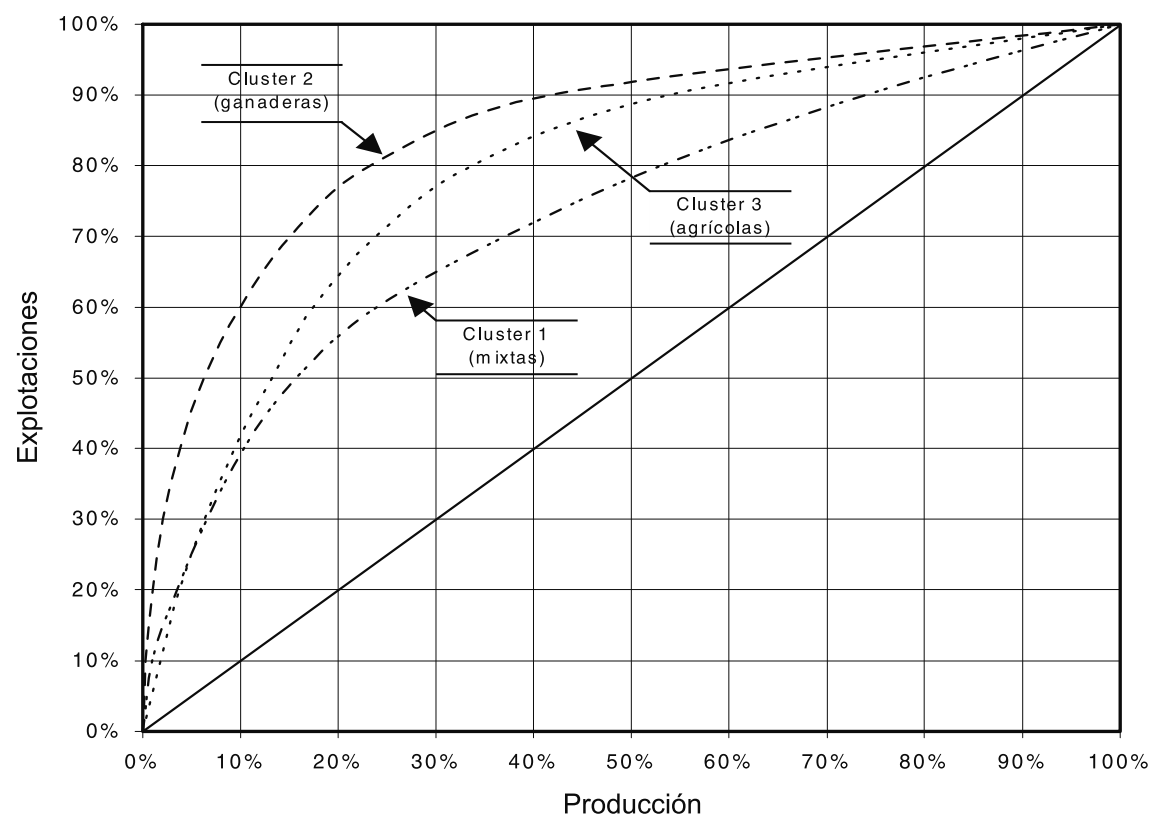

53 Recuérdese que nos encontramos en un ámbito "suburbano" (salvo por lo que respecta a las explotaciones de gran tamaño); y por tanto en él debían encontrarse localizados los tambos, huertas, etc. que surtían a Concepción. En el área 2, zona más rural que Concepción, encontramos también una escasa presencia de equinos en las unidades pequeñas; pero es probable que aquí los bueyes necesarios para los arados y gran parte del vacuno fueran también animales cuidados en la cercanía de la casa por los miembros de la familia, sin necesitar una masiva presencia de equinos, necesaria en las explotaciones grandes, más evidentemente orientadas al vacuno de rodeo. 
La imagen es elocuente: los productores medianos más representativos son los mixtos, pero existe un sector de pequeños productores agrícolas bastante fuerte, si bien la presencia de grandes explotaciones dedicadas al cultivo de trigo determina un movimiento en la curva que la aleja patentemente de la correspondiente a las explotaciones mixtas a medida que crece el tamaño medio de ellas. En cuanto a los ganaderos, de lejos el sector más concentrado, podemos ver que las explotaciones más pequeñas son bastante más "pobres" que las mixtas y agrícolas; y que, por el contrario, las más grandes poseen una porción mayor de la riqueza creada: por decirlo con números, el 10\% más rico de los ganaderos es dueño del 59\% del valor producido, mientras que entre los mixtos ese segmento sólo lo es del $31 \%$ del valor. Por otras parte, $10 \%$ más rico de los grandes productores agrícolas ha producido el $46 \%$ del valor; pero entre ellos el $80 \%$ de las unidades de menor tamaño da cuenta del $34 \%$ del valor total producido.

Pero hay algo más. Volviendo a nuestra hipótesis acerca de que la mayor dedicación a la agricultura antes que a la ganadería por parte de las explotaciones pequeñas se debía a los costos diferenciales de ambas actividades, podemos decir que nuestros datos la apoyan: en efecto, al elaborar las curvas de Lorenz por área (no reproducimos el gráfico por razones de espacio), observamos que la concentración de la producción en el área 3 determina que la tendencia no refleje el peso de la pequeña producción agrícola en el resto de las áreas, que es mucho más importante (si bien la escasa cantidad de casos nos vuelve prudentes con respecto a estas afirmaciones). ${ }^{54}$

Los corolarios de esta peculiar estructura de creación de riqueza son diversos, pero aquí y ahora sólo destacaremos algunos de ellos. El primero tiene que ver con el tipo de mano de obra predominante según la orientación productiva y el tamaño de la explotación: al parecer, en las unidades productivas mixtas y en las agrícolas pequeñas y medianas debió predominar la mano de obra familiar, con contratación eventual de asalariados o, más probablemente, la solicitud de ayuda recíproca a los vecinos en los momentos álgidos del ciclo agrícola o para tareas estacionales (esquila, marcación, castración, etc.). Por otra parte tenemos las grandes unidades productivas (tanto ganaderas como chacras de trigo), que por su misma dimensión debieron ser manejadas fundamentalmente en base a trabajo asalariado. Las grandes chacras trigueras ocupaban un espacio importante

54 Se trata de sólo 3 explotaciones para el área 1, y de 14 para el área 2. Donde más se nota el peso de las pequeñas explotaciones agrícolas es, sin embargo, justamente en el área 2. 
en la producción agraria local y en los mercados de grano; es de pensar que todas esas grandes unidades productivas constituían un desemboque y una opción de empleo aprovechada por individuos temporalmente desocupados que podían tener residencia local (sobre todo en las pequeñas unidades productivas cercanas) o de migración esporádica; los altos salarios pagados en la zona, cuando los comparamos con los usuales en grandes estancias correntinas nos muestran claramente por qué aquélla era neta receptora de migrantes estacionales, circunstancia que se refleja en las cuentas de las estancias, las veces que las mismas nos detallan el origen de los peones. ${ }^{55}$

También podemos apreciar el peso de la mediana explotación y las pautas de inversión que la caracterizaban: al parecer, una mayor propensión hacia la diversificación productiva y a los planteles mixtos, con presencia respetable de ovinos. Asimismo, podemos decir que es probable que las condiciones de frontera abierta (escasa y reciente ocupación humana; tierras abundantes; quizá la compleja situación política con respecto a las colonias portuguesas, que había desembocado en una guerra pocos años antes) hayan determinado un predominio de la ganadería extensiva y probablemente la concentración en pocas manos de planteles ganaderos significativos; asimismo, la existencia de grandes propiedades en las cercanías del único centro urbano local (la villa de Concepción) posibilitó que, en estos años tempranos, el mercado del trigo se constituyera en una opción interesante para algunos de esos grandes propietarios, que se volcaron a la producción agrícola, aun con la competencia de las pequeñas explotaciones campesinas de menores costos productivos. ${ }^{56}$ Resulta también interesante pensar que, antes que a un ansia de acaparamiento de tierras y ganados,

55 Los salarios que paga la estancia del Rincón de Luna hacia 1796-7 sólo llegaban a 3 ó 4 pesos de plata por mes, siendo además la mayor parte de ellos cobrados por anticipado en lienzo, efectos y animales; en la estancia de Pedro García de Zúñiga, en el Gualeguaychú del 1800-3, las remuneraciones rara vez bajan de los 6 pesos mensuales, siendo la mayor parte de las veces de 7 ú 8 , cobrados casi por entero en plata, siendo en general las cuentas deudoras mucho más cortas (y las permanencias también) que en la gran estancia correntina. Ver los libros de cuentas del Rincón de Luna en AGN, IX22-6-7, Temporalidades de Corrientes, 3, 1799-1810; las de la testamentaria de Pedro García de Zúñiga, en AGN, Sucesiones, 5899. Al parecer, los salarios rurales del sur entrerriano eran similares a los de la Banda Oriental, y algo mayores que los de la campaña de Buenos Aires. Ver Gelman: Campesinos y estancieros..., pág. 213.

56 Al fundarse la villa de Concepción, en 1782, uno de los grandes problemas que debió enfrentar su Rómulo, don Tomás de Rocamora, fue justamente la existencia de grandes propiedades que habían sido otorgadas en merced hacía poco tiempo. Los largos informes que remitiera al Virrey, aunque teñidos de fisiocracia, han sido citados repetidas veces como un ejemplo de la particularmente perversa situación de los primeros pobladores campesinos del área, arrinconados por los rebaños de los grandes terratenientes y sin posibilidades de lograr sitio para sus siembras y ganados. Ver al respecto Pérez Colman: Historia..., vol. II, págs. 149 y ss. 
como lo quiere la historiografía tradicional, las verdaderas razones de esa estructura productiva reposen justamente en esas condiciones de frontera y en los costos diferenciales de cada actividad, según la escala empleada en ella y el tipo de recursos en mano de obra disponibles.

\section{Algunas reflexiones finales}

El uso de la técnica de distribución en clusters para el análisis del caso que nos ocupó en las páginas anteriores nos permitió efectuar un agrupamiento operativo de las unidades de explotación que a su vez resultó en una descripción provechosa de sus caracteres: dadas las especificidades del perfil general, la distribución de las unidades en mixtas, ganaderas o agrícolas reflejó no sólo la orientación productiva de las mismas sino que además nos permitió ubicar la información cualitativa dispersa y estudiar las gradaciones de la riqueza agropecuaria a través de una imagen dinámica; la sociedad y la economía locales, que para nosotros permanecían en las sombras por la falta de censos y de otras fuentes complementarias, adquirieron rasgos más claros. Del mismo modo, la distribución en clusters se mostró compatible con otras formas de presentación de datos, ayudando a aprovecharlas en forma complementaria.

Es probable que otras técnicas estadísticas nos hubieran ayudado a obtener resultados igualmente ricos, pero la exigüidad de los datos limitaba fuertemente su uso. La escasa cantidad de casos no justificaba el empleo de técnicas que resultan útiles para el manejo de bases de datos cuantiosas, y emplearlas aquí hubiera parecido un atentado a la parsimonia científica. Por supuesto, la manipulación estadística no suple las falencias de las fuentes; es necesario un previo análisis crítico y admitir que resultará imposible trabajar si no contamos con un mínimo de material aprovechable. No sabemos si será posible contar algún día con información relativa a la totalidad de la fortuna de los productores del norte entrerriano de fines de la colonia, así como probablemente tampoco lograremos nunca reconstruir los límites y características de sus propiedades rurales; hasta tanto, la apelación a algunos instrumentos estadísticos puede mostrarse útil para aprovechar esos registros pobres o insuficientes, y aun llegar a obtener de ellos un análisis un poco más refinado que un simple gráfico de barras. Se trata, en definitiva, de administrar recursos escasos: esto es, de hacer lo más posible con lo poco que está a nuestro alcance. 